$10 / 31 / 01$

\title{
On the Vertical Distribution of Local and Remote Sources of Water for Precipitation
}

\author{
Michael G. Bosilovich ${ }^{*}$ \\ NASA/Data Assimilation Office \\ Code 910.3 Goddard Space Flight Center \\ Greenbelt MD
}

Submitted to Meteorology and Atmospheric Physics

* Corresponding address: Data Assimilation Office, Code 910.3, NASA Goddard Space Flight Center, Greenbelt, MD 20771, mikeb@dao.gsfc.nasa.gov 


\title{
On the Vertical Distribution of Local and Remote Sources of Water for Precipitation
}

\begin{abstract}
The vertical distribution of local and remote sources of water for precipitation and total column water over the United States are evaluated in a general circulation model simulation. The Goddard Earth Observing System (GEOS) general circulation model (GCM) includes passive constituent tracers to determine the geographical sources of the water in the column. Results show that the local percentage of precipitable water and local percentage of precipitation can be very different. The transport of water vapor from remote oceanic sources at mid and upper levels is important to the total water in the column over the central United States, while the access of locally evaporated water in convective precipitation processes is important to the local precipitation ratio. This result resembles the conceptual formulation of the convective parameterization. However, the formulations of simple models of precipitation recycling include the assumption that the ratio of the local water in the column is equal to the ratio of the local precipitation. The present results demonstrate the uncertainty in that assumption, as locally evaporated water is more concentrated near the surface.
\end{abstract}




\section{Introduction}

The relative contribution local and remote geographic sources of water for precipitation have been discussed for several centuries (as summarized by Brubaker et al., 1993). If the local source of precipitation were a dominant factor over continental regions, then the feedback between the land surface and precipitation would be important for synoptic to seasonal time scales. Precipitation recycling is the process by which the local evaporative source of water contributes to precipitation before leaving the local region (as defined by Eltahir and Bras, 1994). In general, precipitation recycling in the United States follows the evaporative annual cycle, reaching a maximum in the summer months (Bosilovich and Schubert, 2001a). Conceptually, locally evaporated water enters the well-mixed planetary boundary layer (PBL), where it can become a source of mass at the convective cloud base. Once entrained into the convective cloud, the local water is carried upward where it can be condensed and precipitate back to the surface. The difficulty, of course, is that not all the water will be entrained into a convective cloud, or the prevailing atmospheric conditions may be unfavorable for precipitation, and the locally evaporated water could also be advected away from the region.

Numerous recent studies have shown that soil water can strongly affect precipitating systems (Beljaars et al. 1996; Bosilovich and Sun, 1999). Soil water feedback can also have a significant impact on the duration of seasonal climate anomalies (Atlas et al., 1993; Oglesby 1991) as well as seasonal predictability (Koster et al. 2000). The immediate impact of a soil water anomaly is on the surface evaporation, or the local source of water. Subsequently, the change in soil water also changes the surface heating, planetary boundary layer thickness and the vertical profile of latent heating (Sun and Bosilovich, 1996). Of course, precipitation anomalies and variability also depend on more than just local surface conditions. Sea surface temperature 
anomalies can influence the large-scale circulation and ultimately the production of precipitation (Mo and Nogues Paegle, 2000). The modulation of the low-level jet in the United States is a key factor in the United States water cycle (Helfand and Schubert, 1995) and especially for long-lived drought and flood (Mo et al., 1997). Also, for a local source of water to affect precipitation, the large-scale environment may need to be favorable for precipitation to occur (Bamston and Schikedanz, 1984). The amount of local water that actually contributes to precipitation, its vertical distribution, and the amount remaining in the column are not typically quantified in numerical simulations.

Simplified models have been developed to diagnose precipitation recycling (Budyko, 1974; Brubaker et al. 1993; Eltahir and Bras, 1994; Burde and Zangvil, 2001). These models include numerous simplifying assumptions, including the use of time averaged (monthly mean) and vertically integrated hydrologic data. The simple models assume that local water becomes well mixed in the vertical column with all other sources of water. Furthermore, the simple diagnostic models do not quantify the remote sources of precipitation. Recently, Dirmeyer and Brubaker (1999) used a quasi-isentropic back trajectory model to compute local and remote sources of water by analyzing three dimensional, six-hourly observation and analysis data. While this lessens the assumptions of the bulk diagnostic models, the physical processes that create the precipitation are statistically computed.

An accurate way of determining local and remote sources of water in GCMs has been developed by Koster et al. (1986) and Joussaume et al. (1986). The methodology makes use of three-dimensional passive constituent tracers, called water vapor tracers (Bosilovich and Schubert, 2001b). In the present paper, we report on results from a short general circulation model (GCM) simulation with water vapor tracers (WVTs). WVTs are three-dimensional model 
variables that use all evaporation from a limited region as a source and moist tendencies proportional to the total water vapor to compute the sink (precipitation). The simulation has been analyzed to determine the geographical sources of water for the vertical column over the United States as well as the sources of water for precipitation. The next section describes the model and WVT methodology. Section 3 presents the analysis of the simulation, WVTs and the geographic sources of water in the column of atmosphere over the central United States.

\section{Model and Methodology}

In this experiment, water evaporated from a limited region is the sole source for a three dimensional global atmospheric constituent. Boundary layer mixing and horizontal advection act on the constituent. Physical processes, such as convection, condensation and rain evaporation are computed in proportion to the model's prognostic water vapor variable (within a three dimensional grid cell). This constituent is called a water vapor tracer (WVT). The model formulation and the WVT methodology follow Bosilovich and Schubert (2001b). Ultimately, the basis for the WVTs was developed from the concepts of Koster et al. (1986) and Joussaume et al (1986). Koster et al. (1986) and Joussaume et al. (1986) used this methodology to simulate the global sources of continental and oceanic water, while Numaguti (1999) used a similar method to simulate the regional sources of water in Eurasia

The base model used in this study is version 3 of the Goddard Earth Observing System (GEOS-3) GCM (Suarez and Takacs 1995). The moisture and tracer advection is calculated by a positive definite semi-Lagrangian method (Lin and Rood, 1996) on the Arakawa C grid, while the temperature advection is computed by a fourth order scheme. The model physics includes: Relaxed Arakawa-Schubert (RAS) convection (Moorthi and Suarez, 1992) with rain evaporation 
(Sud and Molod 1988), parameterization of shortwave radiation (Harshvardhan et al. 1987) and longwave radiation (Chou 1984), and a level 2.5 boundary layer turbulence closure scheme (Helfand and Labraga, 1988). A recent improvement to the GEOS GCM is the addition of the Mosaic land-surface model (Koster and Suarez, 1992).

The prognostic equation for water vapor is,

$$
\frac{\partial q}{\partial t}=-\nabla_{3} \cdot(q V)+\frac{\partial q}{\partial t_{\text {lurb }}}+\frac{\partial q}{\partial t_{\text {cond }}}+\frac{\partial q}{\partial t_{\text {revp }}}+\frac{\partial q}{\partial t_{\text {RAS }}}
$$

At any one point in the atmosphere, the physical tendencies that act on the water vapor are turbulence (turb, including surface evaporation), and the moist tendencies occurring because of large-scale precipitation and Relaxed Arakawa Schubert (RAS) convection parameterizations, which include condensation (cond), rain evaporation (revp) and redistribution by convection $(R A S)$. The transport of water is critical to this experiment. Joussaume et al. (1986) suggest that a positive definite advection scheme is required for tracer transport, and they employed a forward scheme. In the present study, the model calculates moisture and tracer advection by a positive definite semi-Lagrangian scheme developed by Lin and Rood (1996).

In the framework of a GCM, constituents of the atmosphere can be easily incorporated into the dynamical and physical processes, especially if these constituents are passive (i.e. do not affect or interact with the fundamental state variables of temperature, moisture and wind). In general, passive constituents are implemented in the GCM as three-dimensional prognostic variables, and can be referred to as tracers. In the present case, we would like to compute the contribution of water to precipitation in one region that originated as local and remote evaporation regions. To accomplish this, three-dimensional passive constituent tracers are provided an evaporative source for a finite region. The three-dimensional constituents are predicted forward in time (at the model's time step), parallel to the model's prognostic water 
vapor variable. The same physical processes that act on water vapor also act on the passive constituents, including precipitation. Therefore, given a regional source of evaporation, a water vapor tracer (WVT) can be used to determine that region's contribution of water to moisture transport, total column water and precipitation at any point on the globe.

The prognostic equation for any one WVT is,

$$
\left.\frac{\partial q_{T}}{\partial t}=-\nabla_{3} \cdot\left(q_{T} V\right)+{\frac{\partial q_{T}}{\partial t}}_{\text {turb }}+E_{\text {surf }}\right)_{T}+f_{C} \frac{\partial q}{\partial t}_{\text {cond }}+f_{R}{\frac{\partial q}{\partial t_{\text {revp }}}}_{\text {RAS }}{\frac{\partial q}{\partial t_{R A S}}}
$$

Turbulent tendency of the water vapor tracers occurs whenever constituent mass is present, but the surface evaporative source only occurs within a tracer's limited region. Further, the surface evaporative sink of tracers by dew formation is considered proportional to the ratio of WVT and total water vapor near the surface. Tracer water is considered to be well mixed with the total water vapor at each three-dimensional grid point. Therefore, the physical tendencies of WVTs by precipitation processes are computed proportional to the those tendencies of total water vapor. Note that condensation and rain evaporation terms include both large-scale and convective tendencies, and the RAS subscript indicates the convection (or redistribution of water) by the Relaxed Arakawa Schubert convection scheme. The proportionality relationships for condensation $\left(f_{C}\right)$, rain evaporation $\left(f_{R}\right)$ and RAS convective redistribution $\left(f_{R A S}\right)$ are given by,

$$
\begin{aligned}
& f_{C}(L)=\frac{q_{T}(L)}{q(L)},
\end{aligned}
$$

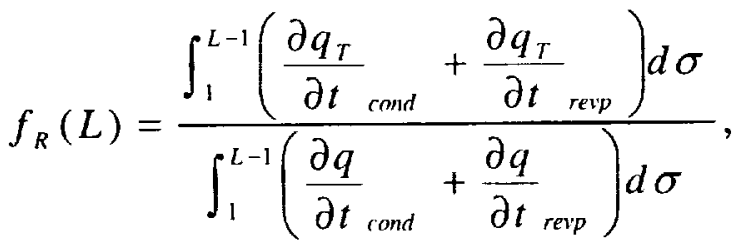




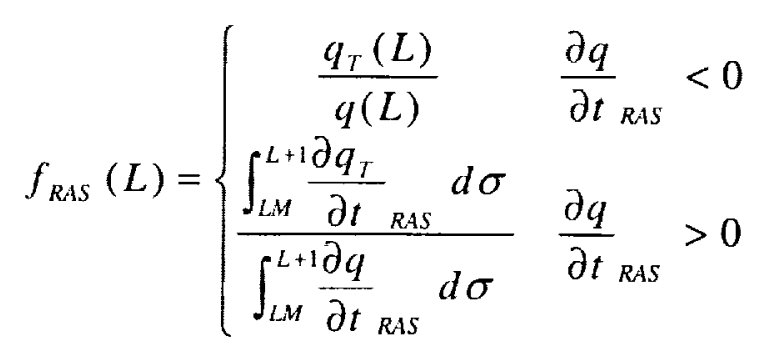

$\mathrm{L}$ is a given model level, and LM is the lowest model level closest to the surface and $\mathrm{L}=1$ is the top of the model $(0.1 \mathrm{mb})$. Integrations are done on the sigma vertical coordinate. In order to close this set of equations, some conditions must be applied. If the proportionality requires the use of the tracer water and specific humidity, the previous time step data is used in the calculation. If tendencies are required, the current time step specific humidity tendencies are used. The following boundary conditions are applied to solve the integrations:

$$
\begin{aligned}
& \frac{\partial q}{\partial t_{R A S}} \leq 0 \quad L=L M
\end{aligned}
$$

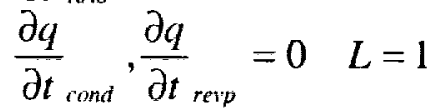

In words, the convective mass flux takes away water from the near surface layers, and the model does not produce condensation and rain evaporation at the top of the model. The proportionality rules can be summarized by: sinks of WVTs consider the ratio of the constituent water to total water vapor at a level (e.g. condensation of water), while the sources of tracer water consider the ratio of vertically integrated stores of tracer water and water vapor during vertical processes at a given time (e.g. rain evaporation).

It should be reiterated that the WVTs are being computed at the model time step as prognostic equations. The WVTs are predicted from model tendencies for water vapor, but do not affect the model's state variables. The prognostic water vapor variable is used in the model precipitation, convection and radiation processes. The precipitation and total water content of any WVT at any time or grid point are computed by, 
$P_{T}=-\frac{p_{s}}{g} \int_{1}^{L M}\left({\frac{\partial q_{T}}{\partial t}}_{\text {rond }}+\frac{\partial q_{T}}{\partial t_{\text {revp }}}\right) d \sigma$

$Q_{T}=\frac{p_{s}}{g} \int_{1}^{L M} q_{T} d \sigma$

(where $p_{s}$ and $g$ are surface pressure and gravitational acceleration, respectively). WVT transport by the horizontal wind $\left(\left\langle q_{T} u, q_{T} v\right\rangle\right)$ is stored at every vertical level. This permits the time averaged transport at any level to be decomposed into mean and transient components following,

$\overline{q_{T} u}=\overline{q_{T}} \bar{u}+\overline{q_{T}^{\prime} u^{\prime}}$
$\overline{q_{T} v}=\overline{q_{T}} \bar{v}+\overline{q_{T}^{\prime} v^{\prime}}$

The GCM diagnostics for precipitation, total precipitable water and moisture transport are computed identically, except using the model's prognostic water vapor variable.

Here, we use the same model and WVT implementation as Bosilovich and Schubert (2001b) to simulate the local and remote sources of water in the United States, with the exception that the source regions are different. Specifically, the regions are expanded for more complete representation of global sources and several additional diagnostic data are included. Source regions are defined in Figure 1. Note that there are 19 large-scale continental and oceanic sources and six regional United States sources defined in this experiment. The sources were defined by inspection of geographical and meteorological features. For example, the Southern Plains (SP) includes the region east of the Rocky Mountains, and encompassing the low-level jet. Large inland bodies of water, such as the Mediterranean Sea and Hudson Bay were included in the Polar WVT for convenience. In this simulation each model grid point contributes to one WVT. The sum of all WVTs is equal to the prognostic specific humidity at every time step in the simulation. 
In this experiment, we simulate one summer season. The model was initialized on May 1 from an arbitrary (but spun up) model simulation. The SSTs are prescribed from monthly means of 1991 observations. The simulation stops on September 1, and the data presented here are seasonal averages of June, July and August (JJA). The model hydrology was validated for six summer seasons in previous work (Bosilovich and Schubert, 2001b). The purpose of this experiment is to evaluate the vertical distribution of local and remote regional WVTs and their transport.

\section{Results}

The moisture transport, total precipitable water and precipitation are evaluated for the regional tracers Southern Plains (SP) and Northern Plains (NP). A third region, Central Plains (CP) is also evaluated, but this region is not associated with a unique WVT. The Central Plains is defined between SP and NP along the same longitudes (bounded by, $105^{\circ} \mathrm{W}$ to $95^{\circ} \mathrm{W}$ and $36^{\circ} \mathrm{N}$ to $44^{\circ} \mathrm{N}$ ). Figure 2 shows the largest WVT percent contributions to JJA vertically integrated WVT transport in the SP, NP and CP regions. During the summer, the largest amount of water moving over the Southern Plains has a source in the tropical Atlantic Ocean and Gulf of Mexico. While a significant amount of water originates in the tropical Atlantic Ocean moving through the Northem plains, the dominant geographical source is the Northern Pacific Ocean. In the Central Plains, the tropical Atlantic and northern Pacific are nearly equal.

The large fraction of transport from the North Pacific was somewhat unexpected, because the lower troposphere the mean moisture transport is dominated by southerly flow east of the Rocky Mountains (Figure 3a). However, in the mid troposphere the moisture transport is dominated by southwesterly flow out of the Pacific Ocean. Transport of the SP moisture is focused on the SP region, but spreads downstream, relative to the low level flow (Figure $3 b$ ). The 
mid-level flow is generally westerly, but the transient component of the transport is from the northeast. Note that the SP mid-level transport is an order of magnitude smaller than the lowlevel transport. The North Pacific transport is disrupted by the Rocky Mountains at the low levels, but only $20 \%$ of the total moisture transport into the northern plains is from the North Pacific Ocean (Figure 3c). In the mid levels, the north Pacific moisture transport can reach $50 \%$ of the total transport into the northern plains. The NPa transient transport is not a factor at in the central United States. The tropical Atlantic Oceanic transport varies with proximity from south to north across the plains (as in Figure 2). But the fraction of the total transport is around $30 \%$ at both the mid and lower levels in the central plains (Figure 3d). In addition to the mean transport, the transient transport of TAt water is a comparable magnitude to the low-level total transient transport over the central United States.

The geographical sources of precipitation and TPW in SP, NP and CP are shown in Figure 4. In general, the percentage of precipitation that occurs from the Northern Pacific WVT is smaller than the percentage of total Northern Pacific WVT in the vertical column. This is especially true for the northern and central plains regions that are in the path of the mid-level flow. The partitioning of CP precipitation and TPW indicates that the fraction of precipitation that occurs from SP evaporation is greater than the fraction of SP water in the column. While the local source has a larger fraction of precipitation than TPW, the NPa contribution is reversed with a larger fraction of TPW than precipitation. This indicates that the efficiency of precipitating the local water is higher than that of the northern Pacific Ocean. Further, the low level transport of NPa water is likely impeded by the Rocky Mountains. The tropical Atlantic source of water shows similar ratios for both TPW and precipitation. This is likely a result of the definition of the 
region, which has a long fetch upstream (relative to the tropical easterlies) and the close proximity of the Gulf of Mexico.

The contribution of local and remote sources of water to the specific humidity profile is presented in Figure 5. Within each region's planetary boundary layer (SP, NP and CP), the percentage of specific humidity from the local sources is much larger than the NPa contribution. However, in the middle and upper troposphere, the NPa contribution is much larger than the local source. The RAS convective parameterization is designed to extract mass at the cloud base, usually within the PBL, and convect it to the cloud top, where the condensate is produced. The convection leaves some of the local water in the upper troposphere as evidenced by the slightly increased fractions at $300 \mathrm{mb}$ than $500 \mathrm{mb}$ of SP and NP water. The tropical Atlantic source of water is well mixed with respect to the total specific humidity compared to the other dominant sources.

Figure 5 indicates that the local water may not necessarily be vertically well mixed with water that is advected into the region. In the SP region, local fraction of SP precipitation is $26 \%$, and the local fraction of SP TPW is $15 \%$. Similarly, the NP region has a larger fraction of local precipitation than local TPW (Figure 4). Generally, most regions show more precipitation from a local source than the TPW, except for the southeastern region (Figure 6). While most of the regions' differences are within a few percent, the differences can be large, even if the integration over the lowest levels is considered. However, even if the percentages of local TPW and local precipitation are close (as in the SE region), significant vertical stratification cannot be ruled out. Figure 7 compares the vertical profiles of local water and all other advected water averaged over the SP and NW regions. The percent contribution of local water is greater in the lower troposphere, and less in the middle and upper troposphere in both regions. Despite the near 
agreement of the TPW and precipitation percentages in the NW region (Figure 6), vertical variations of the local contribution of water are evident. The vertical stratification of local and remote sources of water stands in contrast to the vertically well-mixed assumption included in many bulk analytical recycling models (Budyko, 1974; Brubaker et al., 1993; and Eltahir and Bras, 1994, and summarized by Burde and Zangvil, 2001). The primary example is that the NPa source of water in the column is large, but exists primarily in the mid to upper troposphere, and contributes less to the precipitation.

\section{Summary and conclusions}

The purpose of this paper is to evaluate the vertical distribution of water vapor tracer diagnostics (as applied by Bosilovich and Schubert, 2001b). The fraction of both moisture transport and TPW from the northern Pacific Ocean are larger than the corresponding fraction precipitation that occurs in the Great Plains of the United States. However, the fraction of precipitation that originates as evaporation from the Great Plains is greater than the corresponding fraction of this water in the vertical column. The vertical distribution of the different sources of water indicates that the local Great Plains sources are concentrated in the lower troposphere, while the northern Pacific concentrations are larger in the mid and upper troposphere than near the surface. This is a reasonable response of the model simulation because the convection parameterization entrains water from the planetary boundary layer into the cloud base where it can be convected upward, and ultimately condensed. Also, the Rocky Mountains interfere with the low-level flow of water from the North Pacific Ocean.

The simplified bulk diagnostic models of precipitation recycling are derived by assuming that the local water is vertically well-mixed through the column (reviewed and discussed by Burde and Zangvil, 2001). The well-mixed assumption is generally stated as the ratio of locally 
originating water in the column to TPW is equal to the ratio of locally originating precipitation to total precipitation. The present analysis demonstrates two main points. First, within a fairly small sample of data points, these ratios can be substantially different depending on the vertical distribution of moisture transport and the presence of convective processes. Second, even if the ratios are similar, vertical variations of local moisture in the column are apparent. Previous work with the bulk diagnostic precipitation recycling models accepts this limitation, but its uncertainty has not been quantified. This would tend to increase the uncertainty of bulk estimates due to the lack of physical processes in the vertical, but we have not quantified the uncertainty in the simple recycling model results. Nonetheless, efficient diagnostic estimates of precipitation recycling have been useful in studies of the regional hydrologic cycle, and further development of the simple methods are needed to lessen the restrictive assumptions. The WVT methodology in either GCM or data assimilation systems is more accurate but more computationally expensive.

\section{Acknowledgments}

Drs. Robert Atlas, Siegfried Schubert and Yogesh Sud have provided valuable discussions and support during the course of this project. Greg Walker contributed insightful ideas and programming support during the implementation of the WVTS into the GCM. This effort was partially supported by the GAPP/PACS Warm Season Precipitation Initiative.

\section{References}

Atlas, R. M., N. Wolfson, and J. Terry, 1993: The effect of SST and soil moisture anomalies on GLA Model simulations of the 1988 summer drought. J. Clim., 6, 2034-2048. 
Barnston, A. G., and P. T. Schikedanz, 1984: The effect of irrigation on warm season precipitation in the southern Great Plains. J. Clim. Appl. Meteorol., 23, 865-888.

Beljaars, A.C.M., P. Viterbo, M. Miller, and A. Betts, 1996: The anomalous rainfall over the United States during July 1993: Sensitivity to land surface parameterization and soil moisture anomalies. Mon. Wea. Rev., 124, 362 - 383.

Bosilovich, M. G., and S. D. Schubert, 2001a: Precipitation recycling in the GEOS-1 data assimilation system over the central United States. J. Hydromet., 2, $26-35$.

Bosilovich M. G., and S. D. Schubert, 2001b: Water vapor tracers as diagnostics of the regional hydrologic cycle. J. Hydromet., accepted for publication.

Bosilovich, M. G., and W.-Y. Sun, 1999: Numerical simulation of the 1993 Midwestern flood: Land-atmosphere interactions. J. Clim., 12, 1490-1505.

Brubaker, K. L., D. Entekahabi and P. S. Eagleson, 1993: Estimation of precipitation recycling. J. Clim., 6, 1077-1089.

Budyko, M. I., 1974: Climate and Life. Int. Geophys. Ser., V. 18, Academic Press, San Diego, CA.

Burde, G. I. And Z. Zangvil, 2001: The estimation of regional precipitation recycling. Part I: Review of recycling models. J. Clim., 14, 2497-2508.

Chou, M. D., 1984: Broadband water vapor transmission functions for atmospheric IR flux computations. J. Atmos. Sci., 41, 1775-1778.

Dirmeyer, P. A. and K. L. Brubaker, 1999: Contrasting evaporative moisture sources during the drought of 1988 and the flood of 1993. J. Geophys. Res., 104, 19383-19398.

Eltahir, E. A. B., and R. L. Bras, 1994: Precipitation recycling in the Amazon basin. Q. J. R. Meteorol. Soc., 120, 861-880. 
Harshvardhan, R. Davies, D. A. Randall, and T. G. Corsetti, 1987: A fast radiation parameterization for atmospheric circulation models. J. Geophys. Res., 92, 1009-1016.

Helfand, H. M., and J. C. Labraga, 1988: Design of a non-singular level 2.5 second order closure model for prediction of atmospheric turbulence. J. Atmos. Sci., 45, 113-132.

Helfand, H. M. and S. D. Schubert, 1995: Climatology of the simulated Great Plains LLJ and its contribution to the continental moisture budget of the United States. J. Clim., 8, 784-806.

Joussaume, S., R. Sadoumy and C. Vignal, 1986: Origin of precipitating water in a numerical simulation of July climate. Ocean-Air Interactions, 1, 43 - 56.

Koster, R. D., and M. J. Suarez, 1992: Modeling the land surface boundary in climate models as a composite of independent vegetation stands. J. Geophys. Res., 97, $2697-2715$.

Koster, R. D., and M. J. Suarez, M. Heiser, 2000: Variance and predictability of precipitation at seasonal-to-interannual timescales. J Hydromet., 1, $26-46$.

Koster, R. D., J. Jouzel, R. Suozzo, G. Russell, W. Broecker, D. Rind, and P. Eagleson, 1986: Global sources of local precipitation as determined by the NASAVISS GCM. Geophys. Res. Let., 13, 121-124.

Numagati, A., 1999: Origin and recycling processes of precipitating water over the Eurasian continent: Experiments using and atmospheric general circulation model. J. Geophys. Res., 104, 1957-1972.

Lin, S.-J., and R. B. Rood, 1996: Multidimensional flux form semi-lagrangian transport schemes. Mon. Wea. Rev., 124, $2046-2070$.

Mo, K. C., and J. Nogues Paegle, 2000: Influence of sea surface temperature anomalies on the precipitation regimes over the southwest United States. J. Clim., 13, 3588-3598. 
Mo, K. C., J. Nogues Paegle, and R. W. Higgins, 1997: Atmospheric processes associated with summer floods and droughts in the central United States. J. Clim., 10, 3028-3046.

Moorthi, S. and M. J. Suarez, 1992: Relaxed Arakawa Schubert: A parameterization of moist convection for general circulation models. Mon. Wea. Rev., 120, 978-1002.

Oglesby, R. J., 1991: Springtime soil moisture, natural climatic variability and North American drought as simulated by the NCAR Community Climate Model 1. J. Climate, 4, 890-897.

Suarez, M. J., and L. L. Takacs, 1995: Documentation of the ARIES/GEOS dynamical core: Version 2. NASA Technical memorandum 104606 volume 5, NASA Goddard Space Flight Center, Greenbelt, MD.

Sud, Y. C., and A. Molod, 1988: The roles of dry convection, cloud-radiation feedback processes and the influence of recent improvements in the parameterization of convection in the GLA AGCM. Mon. Wea. Rev., 116, 2366 - 2387.

Sun, W.-Y. and M. G. Bosilovich, 1996: Planetary boundary layer and surface layer sensitivity to land surface parameters. Bound.-Layer Met., 77, 353-378. 


\section{List of Figures}

Figure 1 Geographical source regions for WVTs. Global: NA - North America (only Canada and Mexico), SA - South America, AF - Africa, EU - Europe, AS - Asia, AU - Australia, NPa - North Pacific, SPa - South Pacific, NAt - North Atlantic, TAt - Tropical Atlantic, SAt - South Atlantic, InO - Indian Ocean, Pol - North and south Polar. United States regional: SE - South Eastern, SP - Southern Plains, SW - South Western, NW - North Western, NP - Northern Plains, NE - North Eastern.

Figure 2 Percentage of JJA vertically integrated moisture transport over SP, NP and CP that had a geographic source from selected regions. The source regions presented are the most influential across the Great Plains.

Figure 3 Mean and transient moisture transport (e.g. $\langle\bar{q} \bar{u}, \bar{q} \bar{v}\rangle$ and $\left\langle\overline{q^{\prime} u^{\prime}}, \overline{q^{\prime} v^{\prime}}\right\rangle$, respectively) at $850 \mathrm{mb}$ and $500 \mathrm{mb}$ for (a) total moisture transport, (b) SP WVT transport and (c) NPa WVT transport and (d) TAt WVT transport. The scale vector is shown and varies by level and variable, and has units of $\mathrm{kg} / \mathrm{kg} \mathrm{m} / \mathrm{s}$. In (b), (c)and (d), the mean transport also shows contours of the percentage of total transport.

Figure 4 Percentage of JJA total precipitable water and precipitation that originated from the most influential source regions, area averaged for SP, NP and CP.

Figure 5 Percent contribution of the TAt, NPa, SP and NP regions to the specific humidity profiles ( $q_{T} / q$ at each level) averaged over NP, SP and CP regions. 
Figure 6 Percent contribution of local evaporation to precipitation $\left(P_{T} / P\right)$ and TPW $\left(Q_{T} / Q\right)$, area averaged for the United States regional sources in Figure 1. $Q_{T} / Q(L L)$ indicates the vertical integration over the lowest 11 model levels (roughly up to $700 \mathrm{mb}$ in the vicinity the Unites States).

Figure 7 Percent contributions of the local sources to the vertical profile of specific humidity area averaged for the SP and NW regions. 
7. Figures
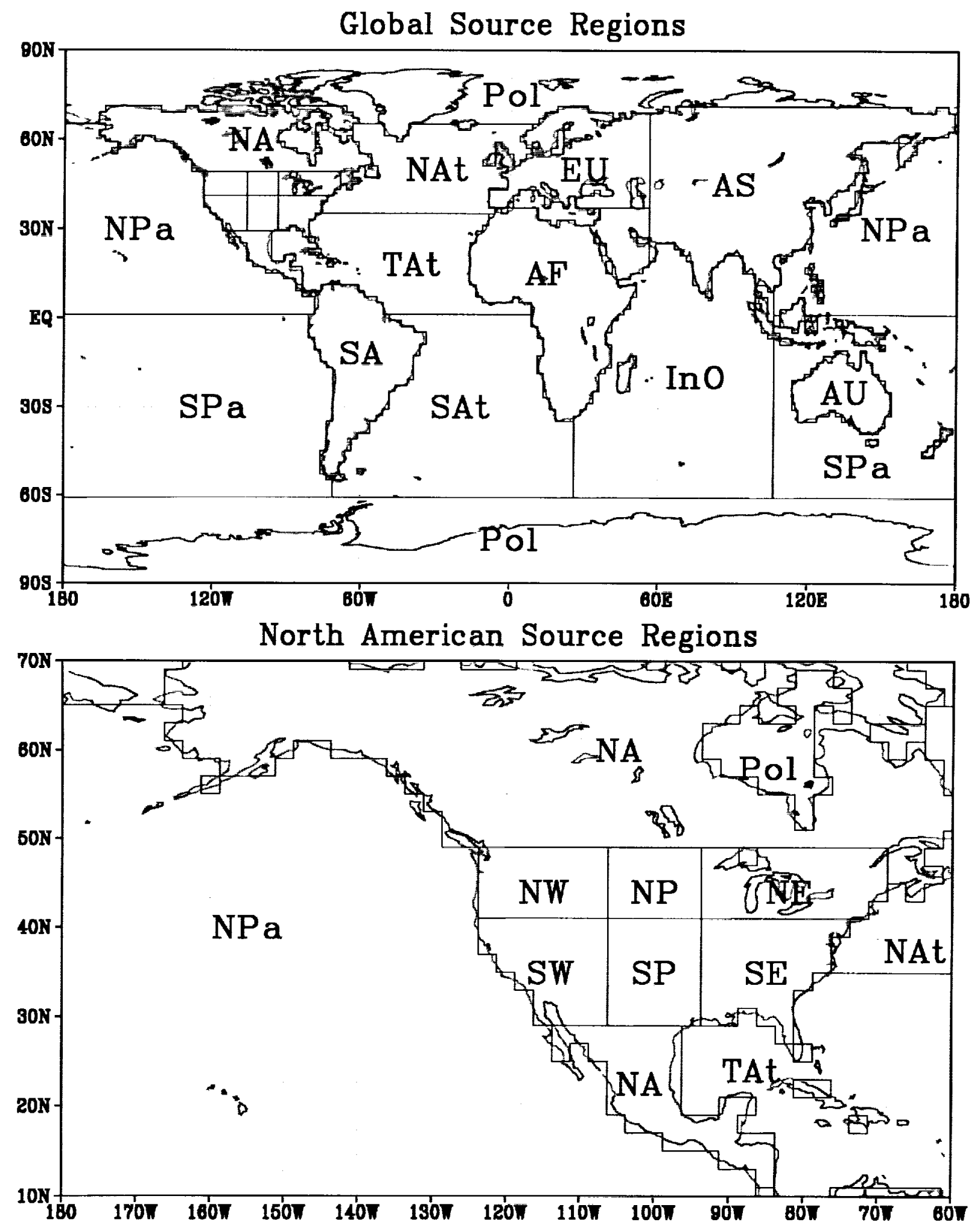

Figure 1 


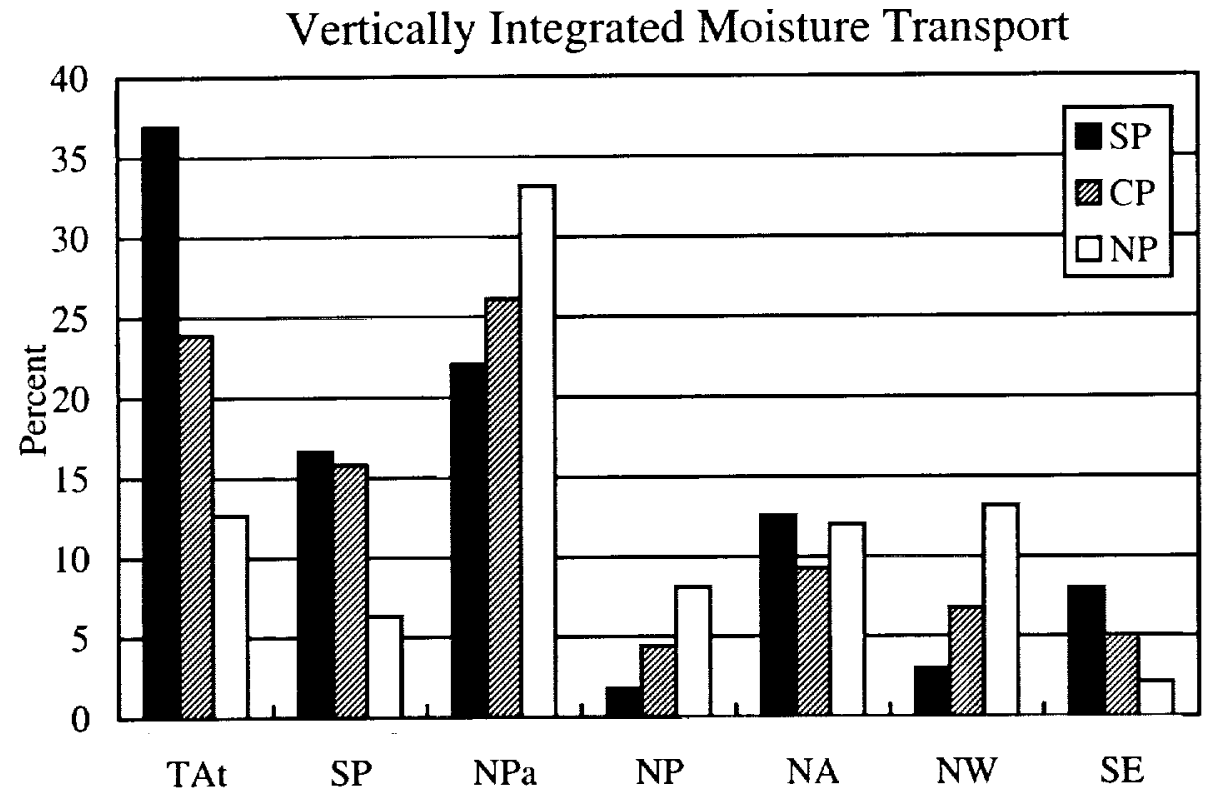

Figure 2 


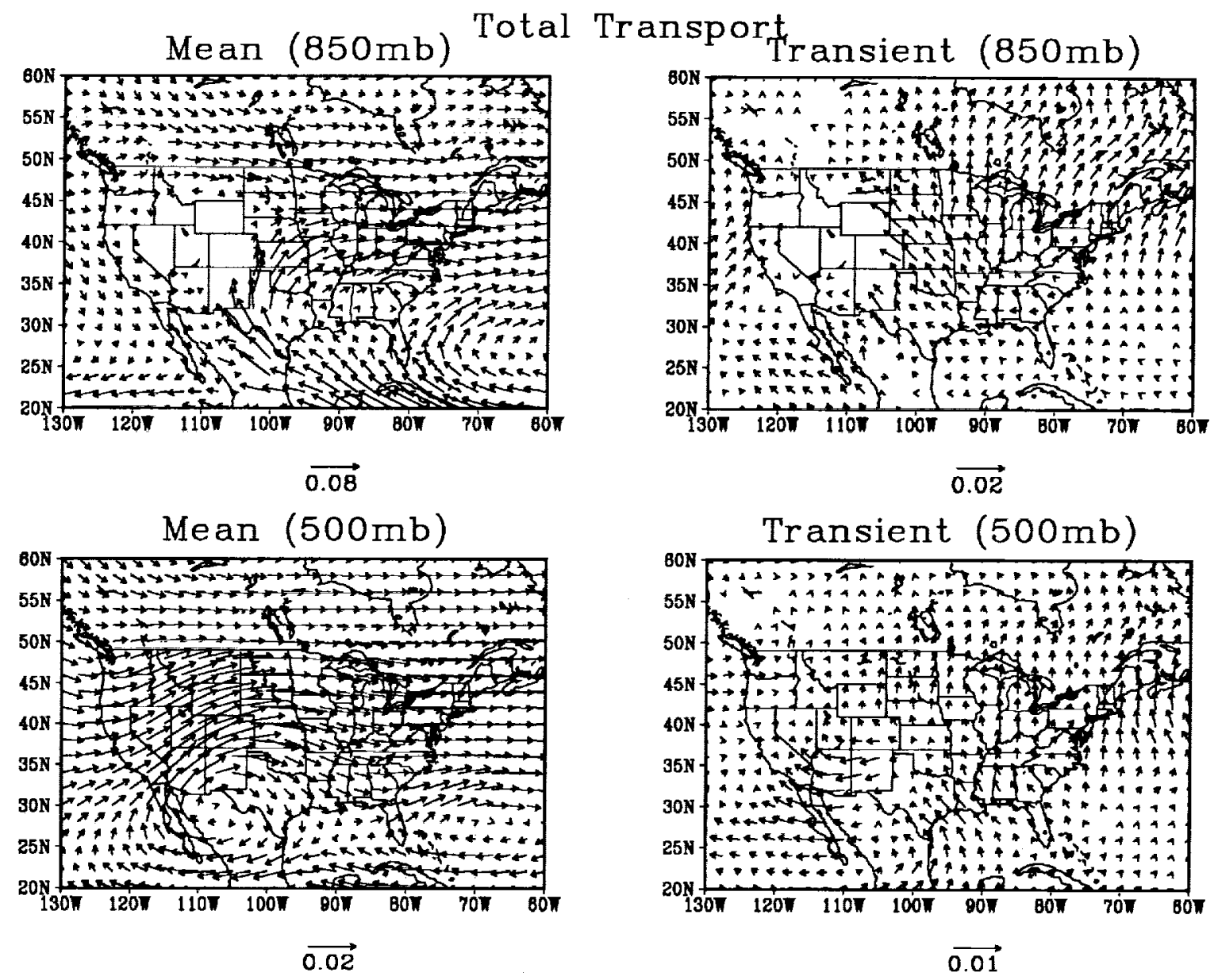

Figure $3 a$ 

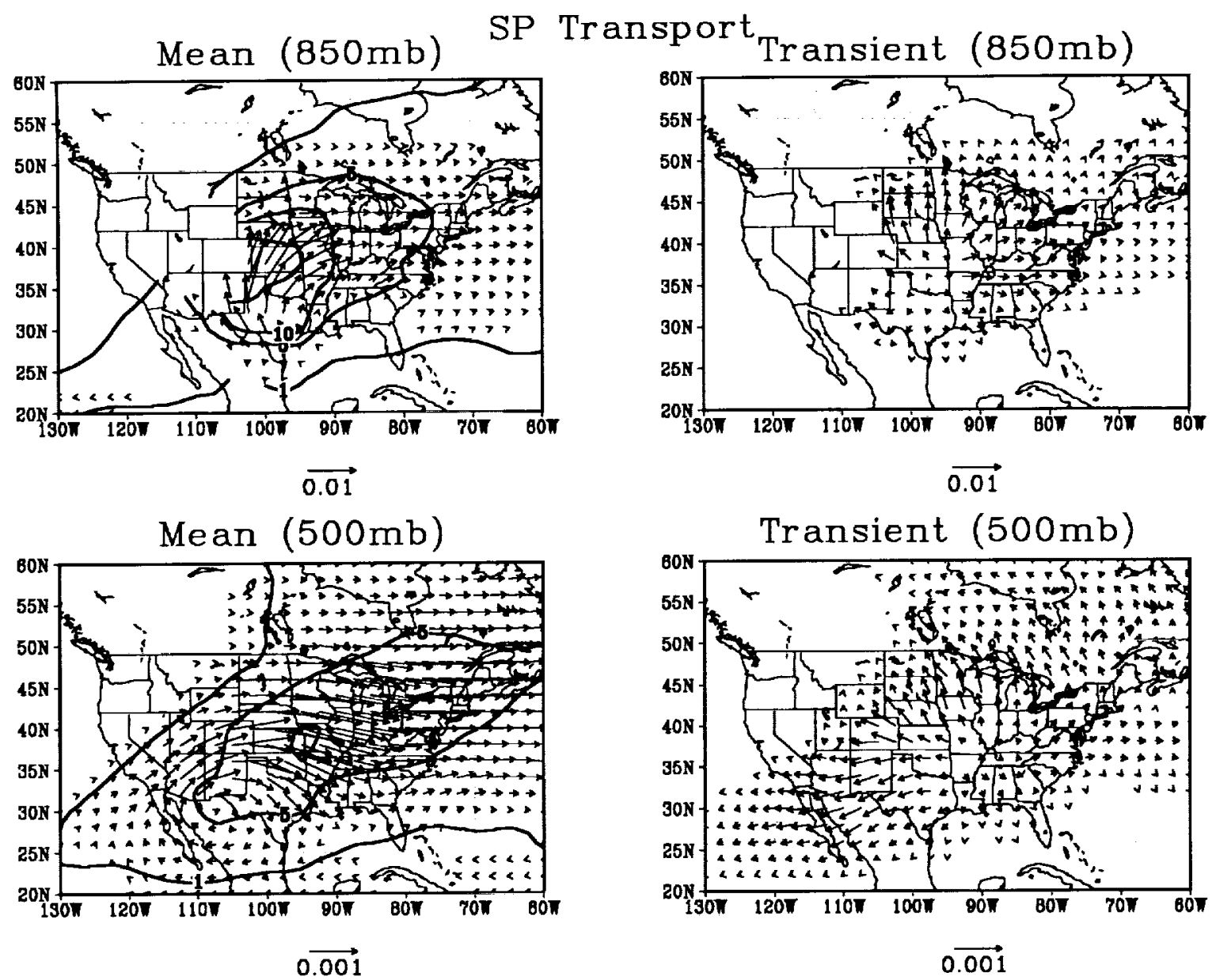

Figure $3 b$ 

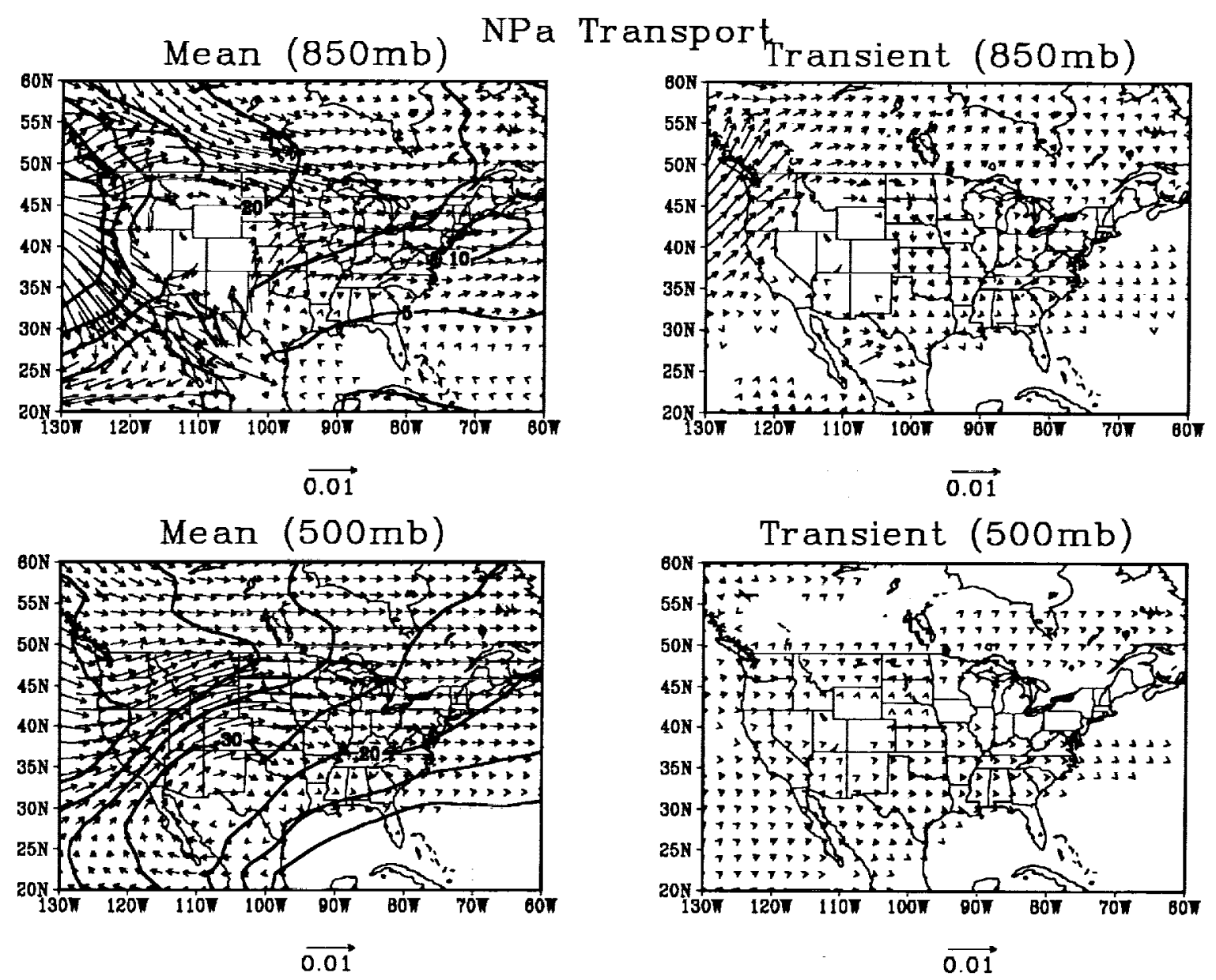

Figure 3c 

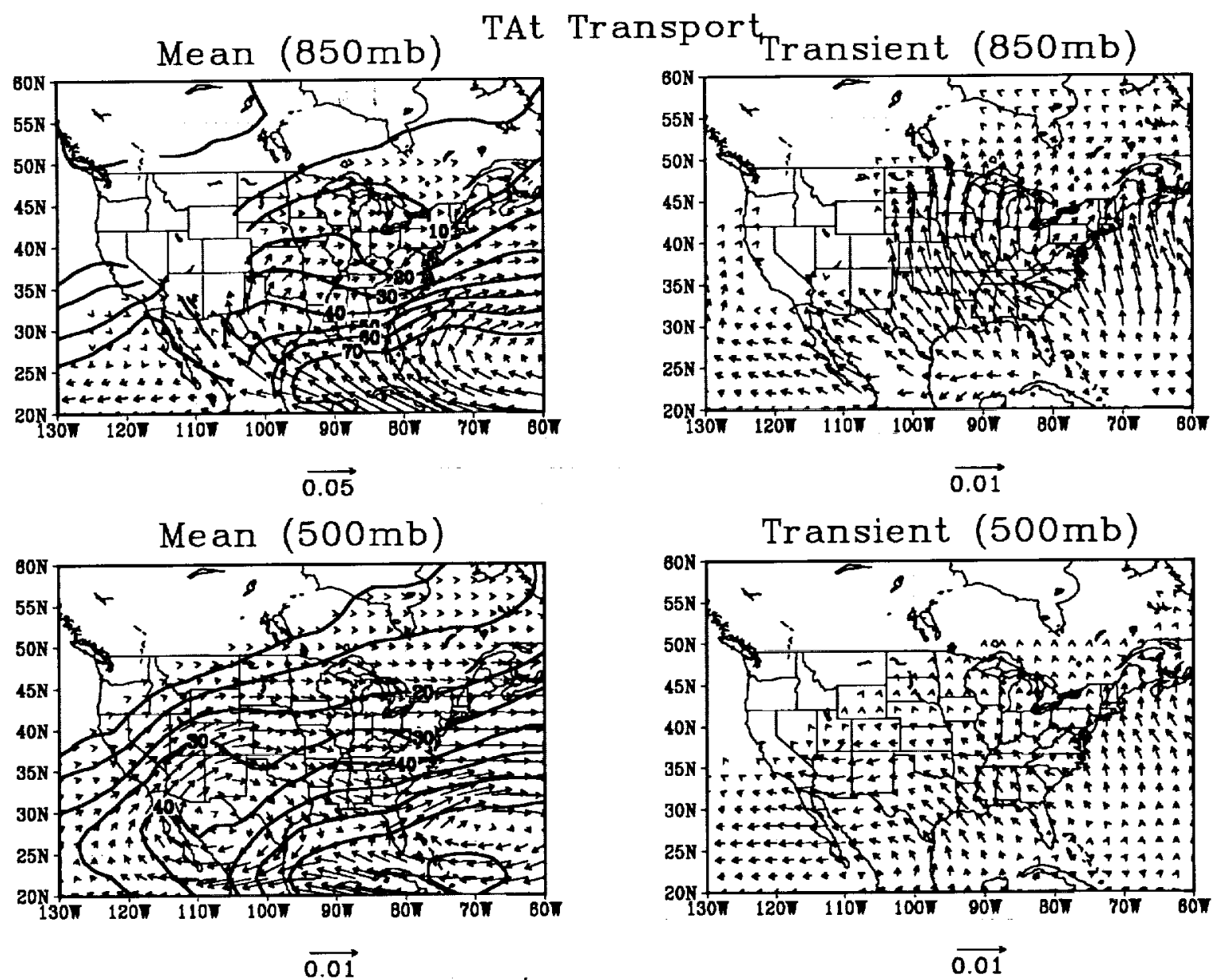

Figure 3d 

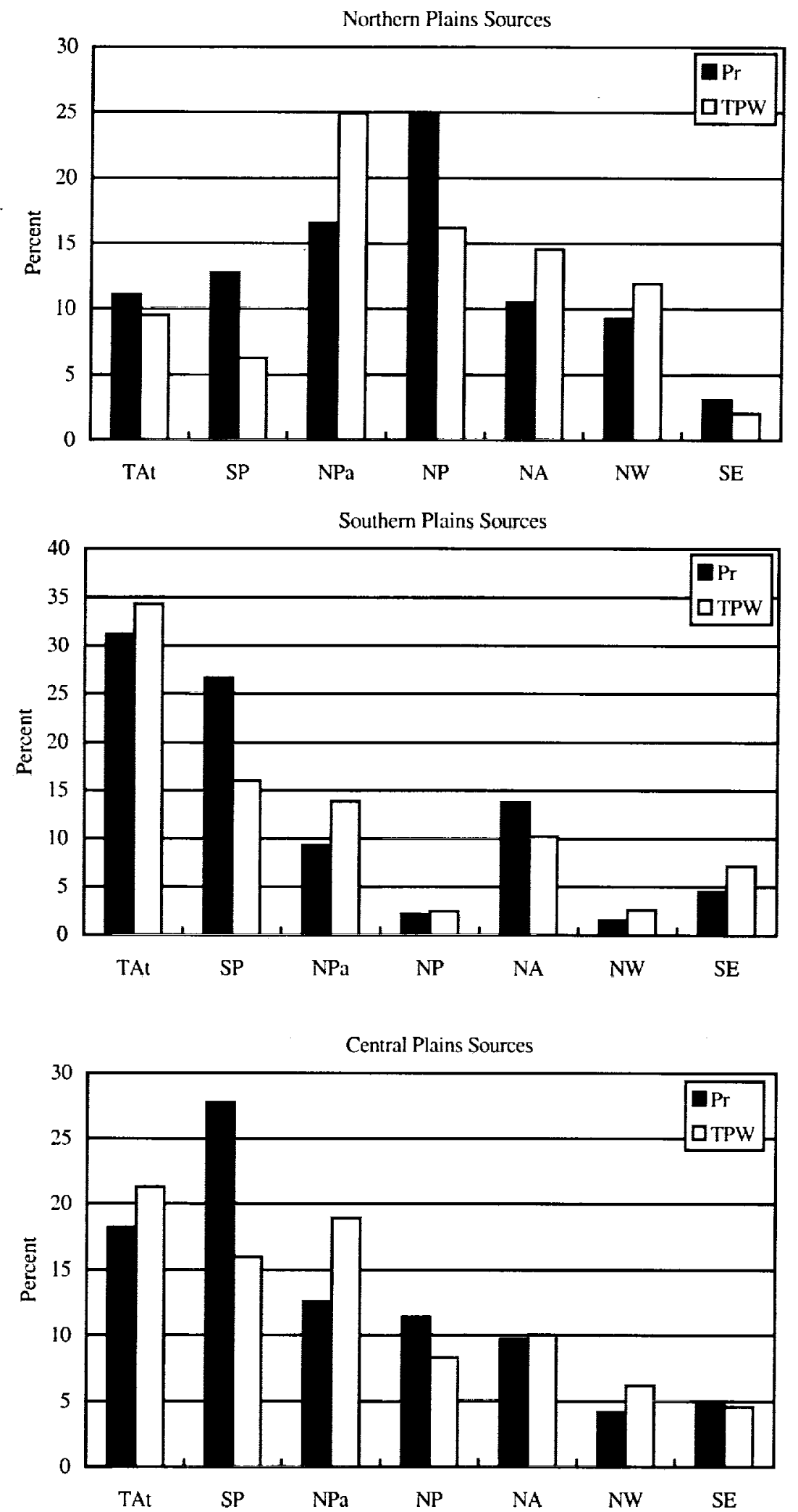

Figure 4 

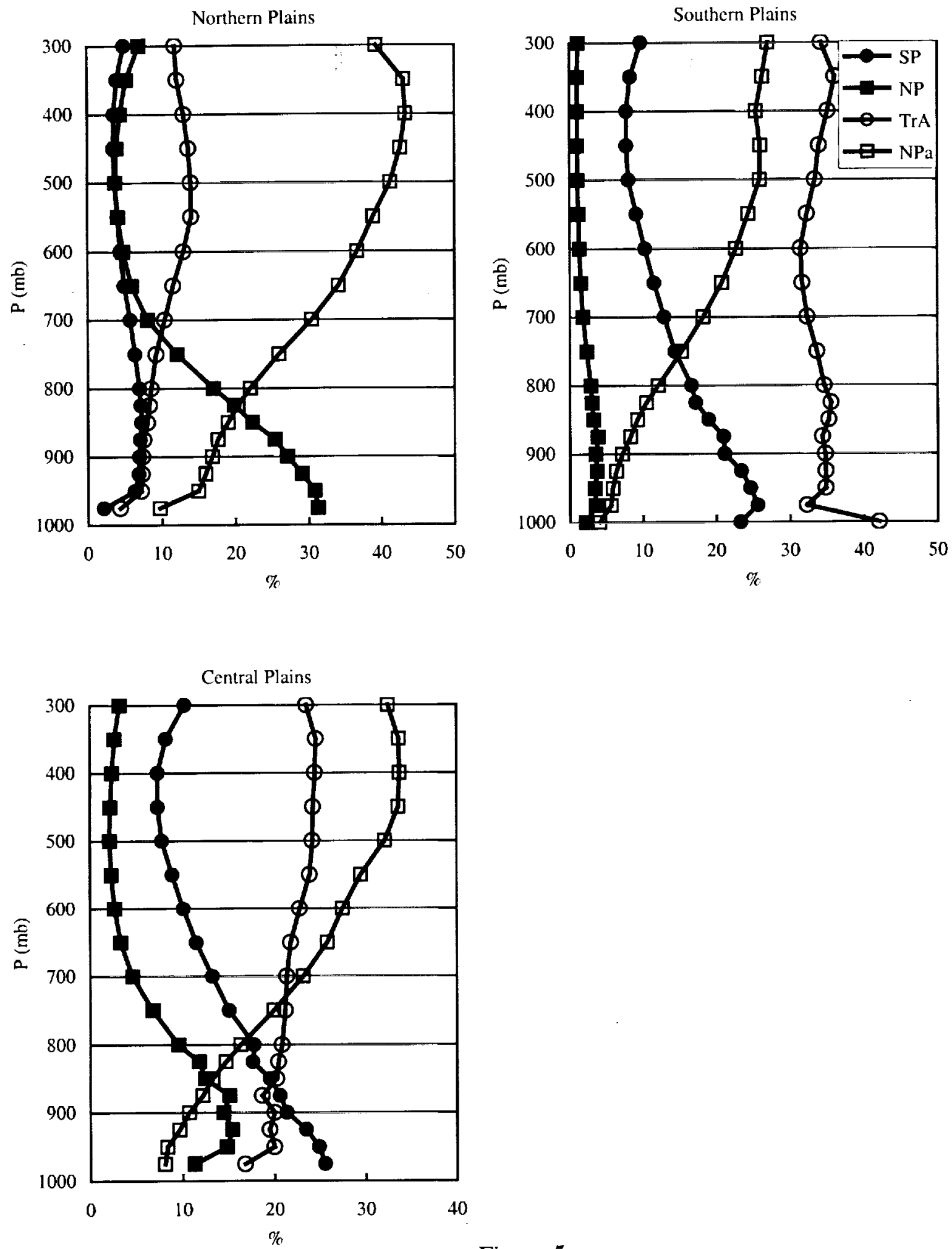

Figure 5 


\section{Local Sources}

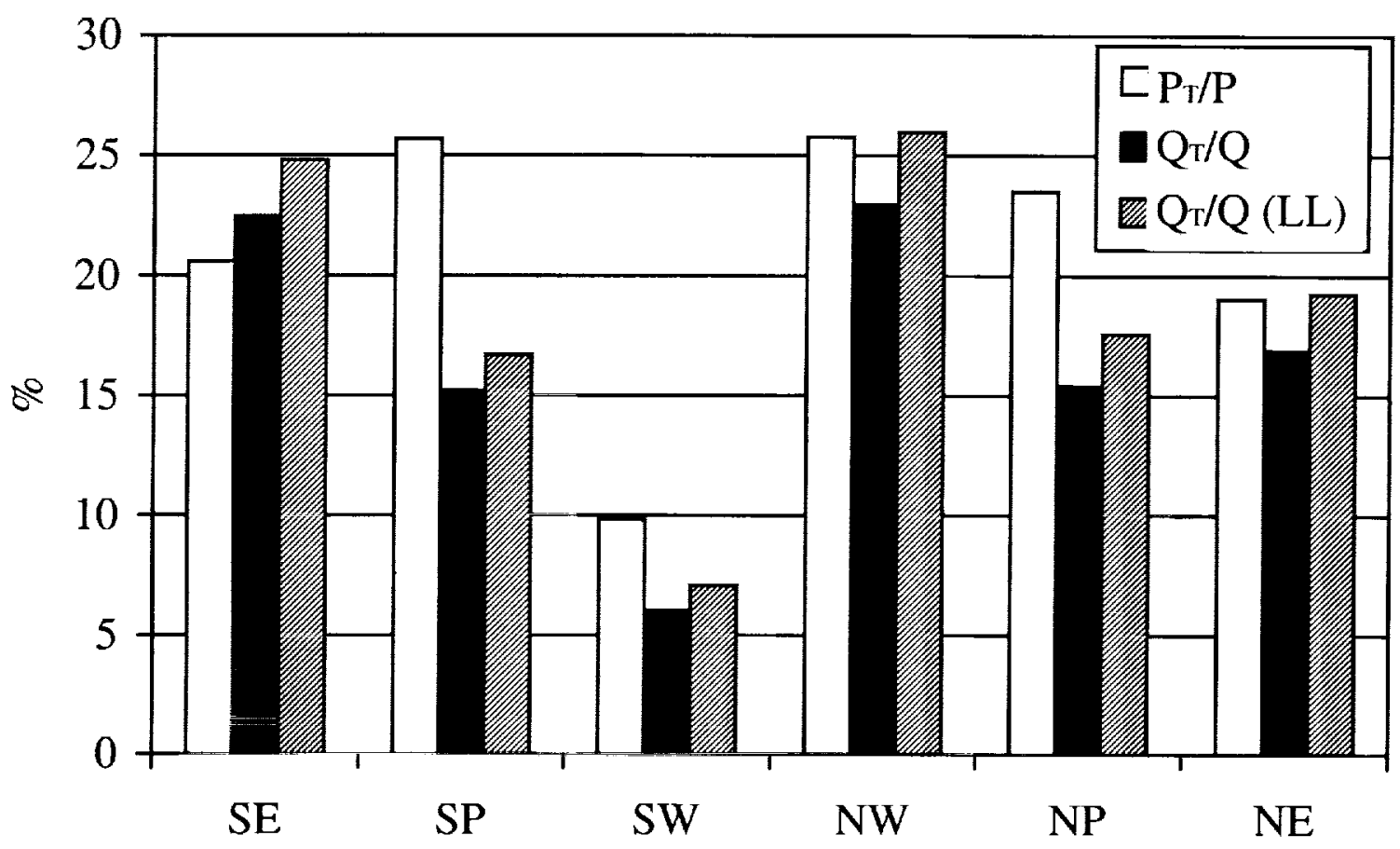

Figure 6 


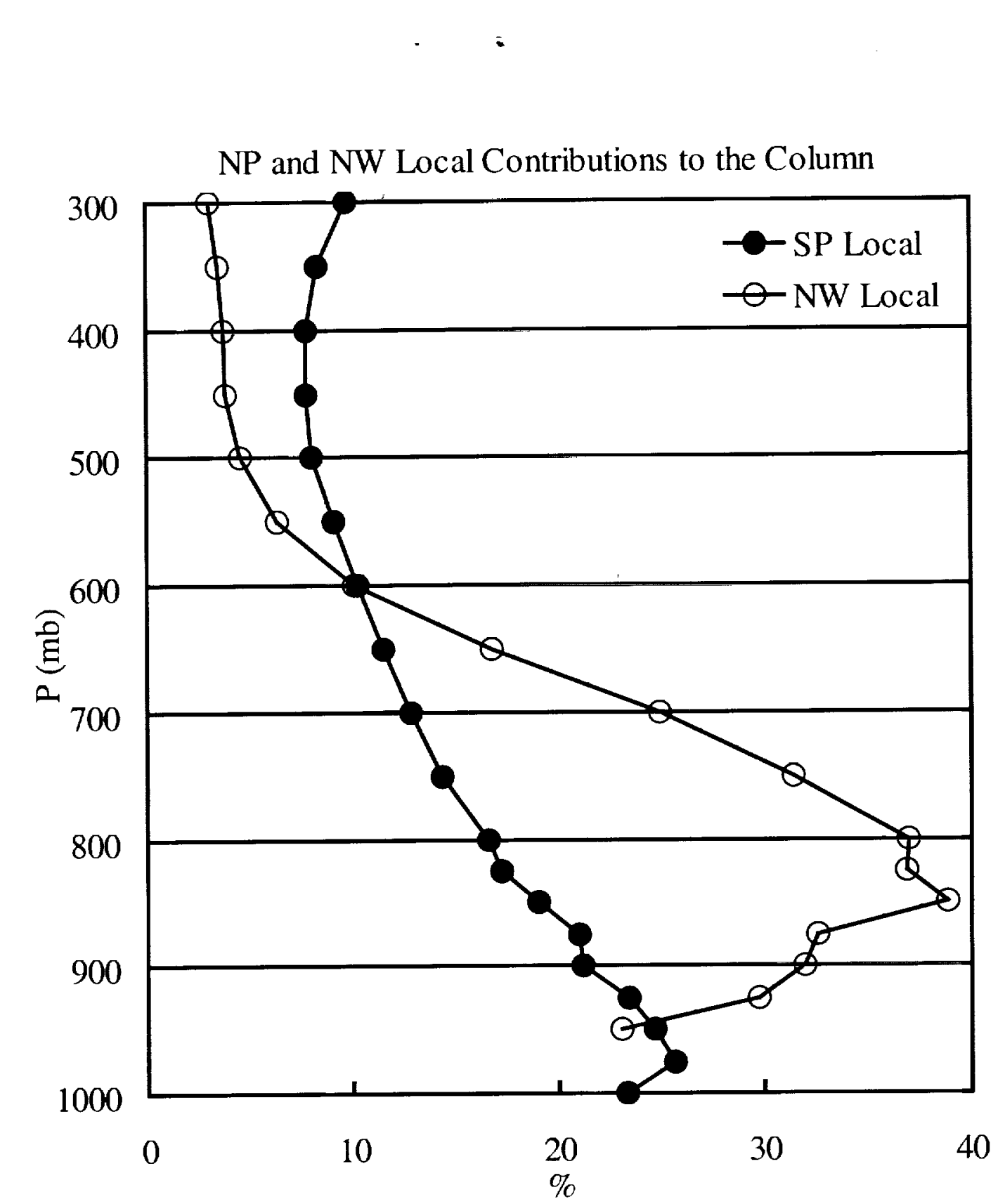

Figure 7 
Popular Summary

On the Vertical Distribution of Local and Remote Sources of Water for Precipitation

By M. G. Bosilovich, NASA DAO, Code 910.3

The water cycle is a serious concern in many, if not all, climate change scenarios. There is some evidence that as global warming progresses, the intensity of the water cycle may increase, most noticeably leading to more frequent long term drought and flood.

Numerical models and data analysis systems are often used to study climate change and the water cycle. Mean components of the water cycle, such as evaporation and precipitation are insufficient to quantify the regional changes to the water cycle. For example, does water evaporate from the surface of one region and precipitate in another, or does it stay in the same region? The answer provides a crucial pathway to understanding the water cycle, water vapor transport and surface/atmosphere interactions that can influence the intensity and duration of regional flood and drought.

In this paper, a new diagnostic tool that tracks the geographic source of water in precipitation events in numerical models is used to evaluate how the model computes precipitation. Given a source region of water entering the atmosphere by evaporation, we can follow the water as it moves and is affected by physical processes, such as condensation. Water that precipitates within the region it originated from is called local precipitation, and water that is transported a distance from a different region is called remote precipitation. Results show that local water in the atmosphere is vertically stratified, larger near the surface and less in the upper troposphere. This stratification allows the local water to provide a significant source of water for convective precipitation, because convective processes entrain water from the lower troposphere. While this is not a new concept, this diagnostic tool allows quantitative evaluation of the local processes and their difference from the influence of remote water. There is a need to better understand these processes in order to advance seasonal and climate predictions. 
, . 